\title{
Effects of Chloroquine and Naphthoquinone on Prothrombin Time and Activated Partial Thromboplastin Time of Swiss Mice
}

\author{
Nkereuwem S. Etukudoh'1, Ntuhun D. Bala², Obeta M. Uchejeso ${ }^{3}$, Hadiza A. Idi'2, \\ Ocheola Oki E. Joyce ${ }^{3 *}$ \\ ${ }^{1}$ Department of Haematology, Federal School of Medical Laboratory Science, Jos, Nigeria \\ ${ }^{2}$ Department of Haematology, Jos University Teaching Hospital, Jos, Nigeria \\ ${ }^{3}$ Department of Chemical Pathology, Federal School of Medical Laboratory Science, Jos, Nigeria \\ Email: ^katejoshua@yahoo.com
}

How to cite this paper: Etukudoh, N.S., Bala, N.D., Uchejeso, O.M., Idi, H.A. and Joyce, O.O.E. (2020) Effects of Chloroquine and Naphthoquinone on Prothrombin Time and Activated Partial Thromboplastin Time of Swiss Mice. Journal of Biosciences and Medicines, 8, 86-94.

https://doi.org/10.4236/jbm.2020.812009

Received: November 5, 2020

Accepted: December 14, 2020

Published: December 17, 2020

Copyright $\odot 2020$ by author(s) and Scientific Research Publishing Inc. This work is licensed under the Creative Commons Attribution International License (CC BY 4.0).

http://creativecommons.org/licenses/by/4.0/

(c) (i) Open Access

\begin{abstract}
Concerns on the coagulation variables, Prothrombin Time (PT) and Activated Partial Thromboplastin Time (APTT) which are part of coagulation parameters used in assessing haemostatsis in haematology, led to the study of the effects of naphthoquinone and chloroquine on the PT and APTT of mice infected with Plasmodium berghei, and treated with graded concentrations of chloroquine and naphthoquinone. Using brain thromboplastin with calcium and rabbit brain cephalosporin ad kaolin respectively the experiment aimed at demonstrating the effect of chloroquine with purity of $99.79 \%$ and naphthoquinone with purity of $97.00 \%$, upon a three-day intraperitoneal administration at concentrations of $0.1 \mathrm{mg} / \mathrm{kg}, 0.5 \mathrm{mg} / \mathrm{kg}, 1.0 \mathrm{mg} / \mathrm{kg}$ and $2.0 \mathrm{mg} / \mathrm{kg}$. Result showed that the APTT and PT of naphthoquinone at $2.0 \mathrm{mg} / \mathrm{kg}$, were 196.67 seconds, and 67.63 seconds respectively, while the APTT and PT of chloroquine were 3.63 seconds and 1.40 seconds respectively for the same concentration. Also, naphthoquinone showed lower APTT but sustained PT at concentrations below $1.50 \mathrm{mg} / \mathrm{kg}$ whereas both APTT and PT increased from concentrations above $1.50 \mathrm{mg} / \mathrm{kg}$. On the other hand chloroquine showed a lowered APTT between 0.00 to $0.15 \mathrm{mg} / \mathrm{kg}$ while PT was sustained, but both APTT and PT increased from concentration of $0.15 \mathrm{mg} / \mathrm{kg}$ gradually. This study conclusively showed that chloroquine has a shorter APTT and PT than naphthoquinones, even though they elicited similar actions. Apart from this, naphthoquinone and chloroquine belonging to the same family, naphthoquinone could be more toxic than chloroquine at the dosages equivalent to $1.50 \mathrm{mg} / \mathrm{kg}$, therefore, any administration of naphthoquinone above this dosage should be closely monitored to avoid any form of danger to the patient.
\end{abstract}




\section{Keywords}

Chloroquine, Naphthoquinone, Prothrombin Time, Activated Partial Thromboplastin Time

\section{Introduction}

Coagulation analyses are not performed routinely in toxicity studies. However, they may sometimes be necessary to determine the pharmacological effect of certain drugs on haemostasis and help in studies involving thrombotic disorders like haemophilia [1] and thrombophilia [2] as well. Coagulation analyses are an array of tests used for investigating the haemostatic status of an individual. For proper functioning of the coagulation system, various substances which may either be promoters or inhibitors of Prothrombin Time (PT) and or Activated Partial Thromboplastin Time (APTT), are required [3].

For a normal haemostasis to be maintained there must be a delicate balance between the activators and inhibitors systems [3]. These regulators keep platelet activation and the coagulation system in check. Abnormalities can lead to an increased tendency towards thrombosis [4]. Therefore, disorders of any of these systems can lead to an increased risk of bleeding (hemorrhage or clotting thrombosis) [4] [5].

Several tests are used to assess the function of the coagulation system. They include: Prothrombin Time (PT) test, Activated Partial Thromboplastin Time (APTT) test, Fibrinogen testing, platelet count, platelet function test, Thrombin Clotting Time (TCT), bleeding time, mixing test, coagulation factor assay, D-dimer, Euglobin Lysis Time (ELT) [6]. The contact pathway is initiated by activation of the contact factors of plasma and can be measured by APTT test. The normal Activated Partial Thromboplastin of mice, rat and guinea pig is 15 - 30 seconds [7], as a result, this work will seek to compare and show the effects of chloroquine and naphthoquinone on the activated partial thromboplastin time (APTT) and the prothrombin time (PT) in mice so as to see its effects on clotting upon administration.

The tissue factor pathway is initiated by release of tissue factor and can be measured by the (PT) test. The PT results are often reported as a ratio (INR value) to monitor dosing of oral anticoagulant such as warfarin. Animal studies show that normal range of PT of mice is 11 - 14 seconds [8].

In a previous study on effects of chloroquine on the complement and coagulation systems, it was noted that the activation of the classical pathway of complement by antibody coated sheep erythrocytes and aggregated $1 \mathrm{gG}$ was blocked by [9]. Similarly, chloroquine prevented normal rabbit erythrocytes and Zymosan from activating the alternative pathway of complement [9]. The activation of C3 by immune complexes of different solubilities also was inhibited by chloroquine [10]. Chloroquine abrogated the clotting of plasma by calcium chloride and thrombin [10]. This effect can be reversed by the addition of excess throm- 
bin but not of calcium chloride [10]. Chloroquine was also found to enhance degradation of FXIII in fibroblasts [11].

Another study on effect of p6304 (2-chloro-3-(4-hexylphenyl)-amino-1,4-naphthoquinone) as a novel antithrombotic agent was investigated, alongside a naphthoquinone NQ304. The NQ304 was found not to affect the coagulation system, since it did not change the APTT and Thrombin Time (TT). The agent prevented death due to pulmonary thrombosis by the platelet aggregates in mice in vivo. In the mouse tail bleeding time test, NQ304 showed a significant prolongation of the tail bleeding time in conscious mice [12].

Naphthoquione and chloroquine are drugs used in the treatment of malaria parasitaemia. Malaria is a disease caused by the parasites of Plasmodium spp. It is a serious problem particularly in the tropical and third world countries. The disease is typically transmitted by the bite of an infected mosquito. The persistence of malaria as a public health problem, which is partly as a result emergence of Plasmodium spp. resistance to antimalarial drugs is leading to increased morbidity and mortality [13] [14] [15], but according to literature, these drugs are no longer choice drugs for malaria treatment since they are used in the treatment of other diseases.

Although allergic reaction from supplementation is possible, there is no known toxicity associated with high doses of the phylloquinone or menaquinone forms of vitamin $\mathrm{K}$ and therefore no tolerable intake level has been set. However, vitamin $\mathrm{K} 3$ (menadione), a synthetic form of the vitamin $\mathrm{K}$ is demonstrably toxic. The FDA has banned this from over the counter supplements because large doses have been shown to cause allergic reactions, hemolytic anemia and cytotoxicity in liver cells, but the comparison between chloroquine and naphthoquinone has not been considered on the basis of its effects on APTT and PT.

Phylloquinone and menaquinone are capable of blocking the blood thinning action of anticoagulants like warfarin, which work by interfering with the action of vitamin $\mathrm{K}$, they also reverse the tendency of these drugs to cause arterial calcification in the long term [16].

Calcium and phospholipids are required for the kinase and thrombokinase complexes to function. Calcium mediates the binding of complexes via the gamma-carboxyl residues on FX and FIX to the phospholipid surfaces expressed by platelets, as well as procoagulant microparticles or microvesicles shed from them [3], but not much is known about the effects of chloroquine and naphthoquinone in graded concentrations on APTT and PT and its interplay with procoagulants as well as clotting factors.

The study was aimed at determining the effect of naphthoquinone and chloroquine on Prothrombin Time and Activated Partial Thromboplastin Time.

\section{Materials and Method}

\subsection{Mice}

Thirtytwo weeks old Swiss Mice (20 g - $40 \mathrm{~g}$ ) were obtained from the Department of Pharmacology Animal House, University of Jos, Plateau State and al- 
lowed to acclimatize to their house well ventilated and sanitized animal research house in the Federal School of Medical Laboratory Science, Jos. Mice were chosen for this study because their clotting system is similar to that of human [8], The mice were all fed with pelletized mice grower and water ad libitum, here the pellets where molded into a ball like mass, with the help of water which was added to soften the pellets and enable binding, the balls were later placed under the sun to dry out. Three of these balls were placed in the cages, with a 1.5 liter of water bottle. The mice fed whenever they were hungry. Their diet was not at anytime restricted.

\subsection{Drugs}

The most potent compound in naphthoquinone group: 2-amino-3-chloro-1,4naphthoquinone with a purity of $97.00 \%$ was obtained from Aldrich chemical CO., WI, USA. Chloroquine diphosphate was obtained from Jos University Teaching Hospital, Jos. Aralen product, with a purity of $99.79 \%$, manufactured in New Jersey, United State of America.

\subsection{Test Reagents}

Prothrombin Time test reagent (Plasmascann ${ }^{\circledR}$ Thromboplastin calcia) manufactured by Quimica Clinica Aplicada East Amposter, Spain, with LOT number B40157.

Activated Partial Thromboplastin Time reagent (Haemoscann ${ }^{\circledast}$ APTT reagent) manufactured by Atlas Medical Cambridge with LOT NO: S40105.

\subsection{Grouping of Mice}

The mice were grouped into three, Group 1 consisted of six mice which were used as control. Group 2 consisted of 12 mice which were further divided into four groups of three mice each. Group 3 consisted of 12 mice which were further divided into four groups of three mice each. Three mice out of the six in the first group (Group 1) were given distilled water and the other three were given tween 20. The second group (Group 2) received chloroquine in four different doses. The third group received naphthoquinone in four different doses.

\subsection{Drug Preparation and Administration}

Chloroquine and naphthoquinone (1,4-naphthoquinone), both in the doses of $0.1 \mathrm{mg} / \mathrm{kg}, 0.5 \mathrm{mg} \cdot \mathrm{kg}^{-1}, 1.0 \mathrm{mg} \cdot \mathrm{kg}^{-1}$ and $2.0 \mathrm{mg} \cdot \mathrm{kg}^{-1}$ were administered intraperitoneally as distilled water and tween 20 were also given to the control group. The doses were given for three consecutive days after which they were left untreated for another three days before they were sacrificed. Doses were calculated in line with first principle for both chloroquine and naphthoquinone for uniformity.

\subsection{Sample Collection}

The mice were placed in desiccators containing chloroform and were anesthe- 
tized. The thoracic cavity was opened and blood was collected through cardiac heart puncture to avoid contaminations of any type into a $1 \mathrm{ml}$ syringe containing $0.1 \mathrm{ml}$ of 3.8 tri-sodium citrate. Each blood sample was well mixed with the anticoagulant and transferred into sample bottles (plastic) for separation of plasma from blood cell. The plasma was obtained and used for the investigation.

\subsection{Prothrombin Time and Activated Partial Thromboplastin Time Tests}

The tests were carried out using the techniques and methods of [6].

\subsection{Method of Data Analysis}

Data were expressed as mean \pm SEM and analyzed using Student's t-test ANOVA was used where necessary and $\mathrm{p} \leq 0.05$ was considered significant.

\section{Results}

The effect of chloroquine and naphthoquinone on prothrombin time and activated partial thromboplastin time of Swiss Mice was studied and the following results were obtained.

\section{Discussion}

The effects, of naphthoquinone and chloroquine on the prothrombin time (PT) and the activated thromboplastin time (APTT) on Swiss Mice infected with Plasmodium berghei were investigated.

The results for naphthoquinone shows that for the control, the APTT was higher (41.33 \pm 15.59 seconds) than the PT which was (11.67 \pm 4.50 seconds), these serve as a reference point for the various doses of naphthoquinone as seen in Figure 1 and Figure 2 respectively. The second group of Swiss Mice treated with $0.1 \mathrm{mg} / \mathrm{kg}$ of naphthoquinone, showed a decrease in APTT $(35.53 \pm 8.21$

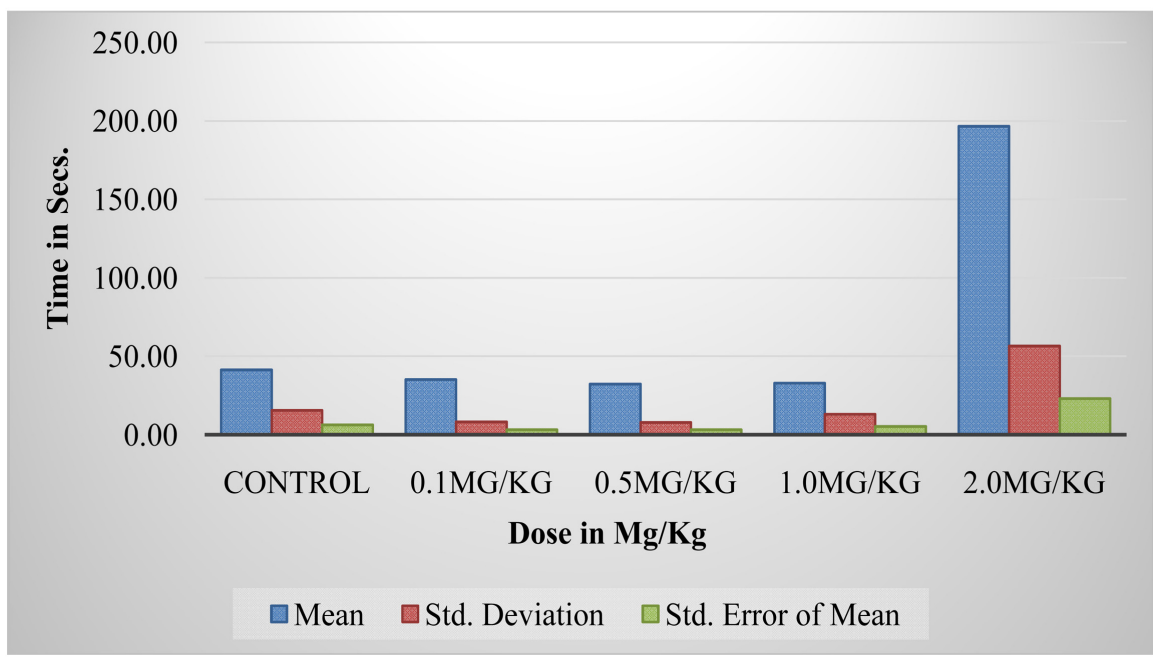

Figure 1. Effect of naphthoquinone on APTT in Swiss Mice. Data are presented as: mean, standard deviation and standard error of mean. 


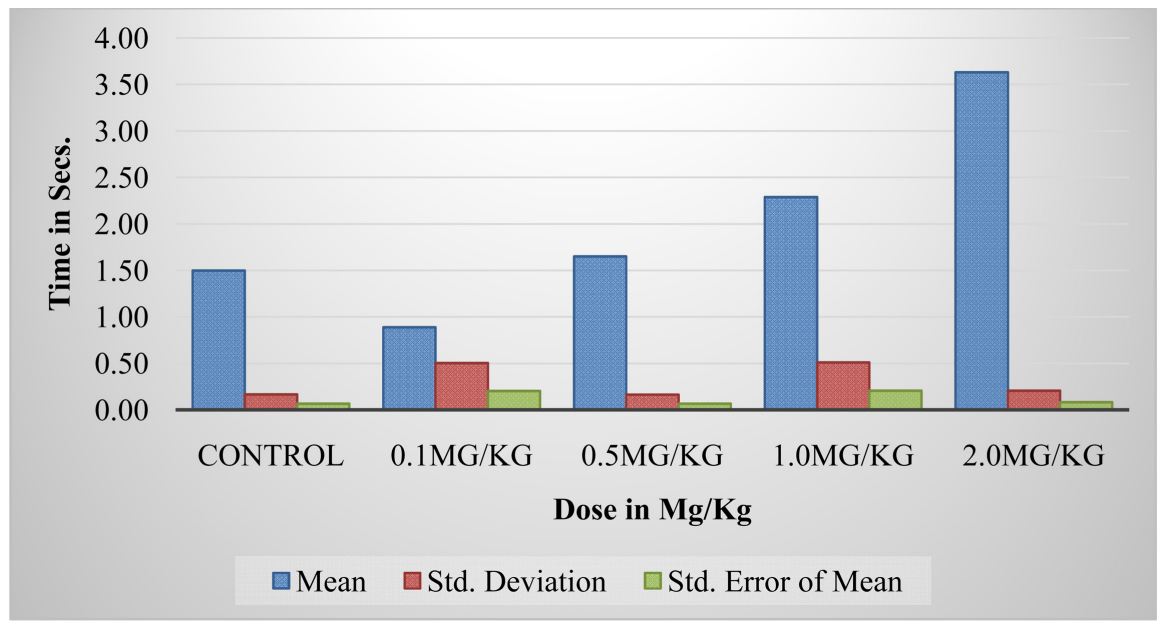

Figure 2. Effect of chloroquine on APTT in Swiss Mice. Data are presented as: mean, standard deviation and standard error of mean.

seconds) and PT (10.67 \pm 2.58 seconds) when compared with the control in Figure 1 . This shows that there may be a likelihood of elevated factor VII which could be the result of an acute phase reaction, the bloods reaction to acute tissue inflammation or trauma. It could also mean that there are circulating anti-coagulants which tends to shorten APTT, a situation known as disseminating intravascular co-agulation (DIC). The PT only increased slightly staying within range of that obtained with the normal control.

For the third group of mice was administered $0.5 \mathrm{mg} / \mathrm{kg}$ of naphthoquinone, there was a further decrease in APTT ( $32.33 \pm 7.97$ seconds $)$ and a PT of $(10.00 \pm$ 1.84 seconds) seen in Figure 1 and Figure 2 respectively, which agrees with earlier studies by [14] who noted a decrease in some haematological parameters of plasmodium infected mice administered with chloroquine and naphthoquinone.

This shows a further intense acute tissue inflammation with a sustained PT showing apart from the presence of Lopus anti-coagulant (LA), a defect in (factors VII, IX, or XI) their functions being quite intertwined, factor VII (f VII) serves to initiate the process of co-agulation in conjunction with the Tissue Factor (TF) which is factor III. This occurs only when there is a vessel injury; tissue factor at this point is exposed to the blood and circulating factor VII. While tissue factor is a transmembrane glycoprotein expressed in the perivascular tissue as main initiators of in vivo blood clotting, it forms a complex with factor VII to activate factor IX. Both pathways interlace with the activation of factor IX which leads to the cleavage of prothrombin, (factor II) to thrombin (factor IIa). Factor $\mathrm{XI}$ is a zymogen of a blood co-agulation protease, factor Xia, which contribute to homeostasis through activation of factor XI. This disagrees with the work of [12] which says that a newly synthesized naphthoquinone NQ304 had no effect on PT and APTT but prevented thrombosis due to its ability to prevent platelet aggregation.

Mice that were given $1.0 \mathrm{mg} / \mathrm{kg}$ dose of naphthoquinone, showed an increase in both APTT (33.01 \pm 13.14 seconds) and PT (11.33 \pm 3.78 seconds). This slight 
increase in both APTT and PT could be indicative of likely Willebrand disease, liver disease, defects in factors (I, II, V, and X) as well as DIC.

The group of mice that were given $2.0 \mathrm{mg} / \mathrm{kg}$ of naphthoquinone showed a remarkable increase in APTT (196.67 \pm 56.61 seconds) as well as PT (67.63 \pm 19.07 seconds), with the differences being very significant when compared to those of the control. This shows most likely, the presence of spontaneous bleeding as well as advanced stage of DIC.

Summarily, naphthoquinone doses below $2.0 \mathrm{mg} / \mathrm{kg}$ may not be toxic, reduces APTT while sustaining PT, but doses of $2.0 \mathrm{mg} / \mathrm{kg}$ and above may be toxic and cause spontaneous bleeding as well as liver damage among other conditions.

For the chloroquine, the first group of mice which served as control had APTT $(1.51 \pm 0.17$ seconds $)$ and PT of $(0.21 \pm 0.13$ seconds $)$ as seen in Figure 3 and Figure 4 respectively. This serves as a reference point for other doses with chloroquine.

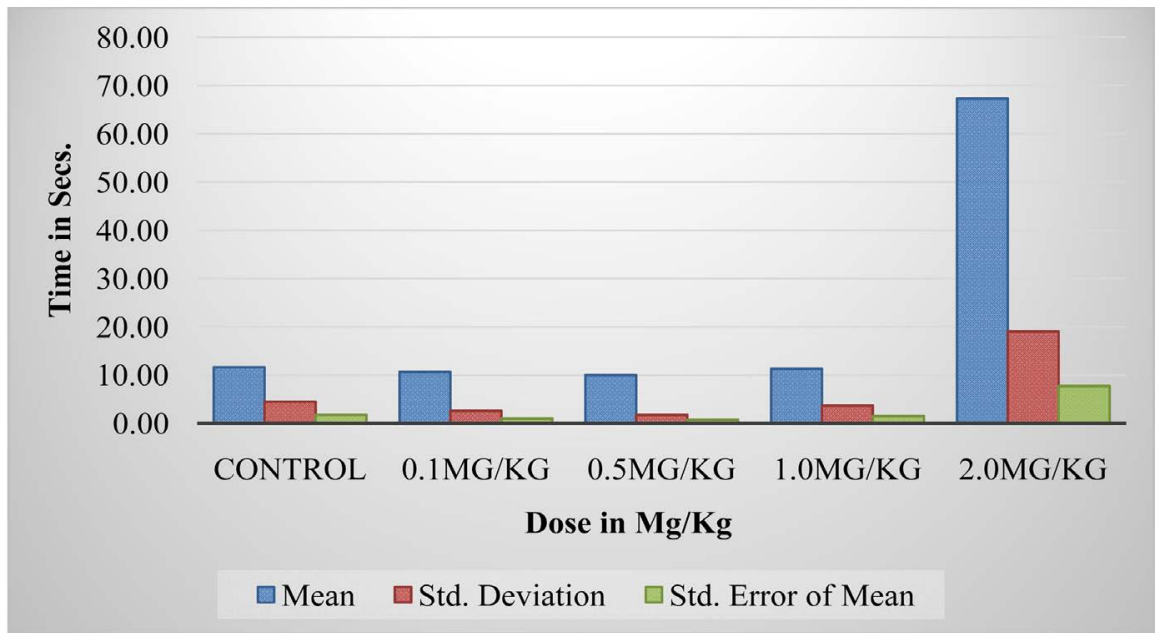

Figure 3. Effect of naphthoquinone on PT in Swiss Mice. Data are presented as: mean, standard deviation and standard error of mean.

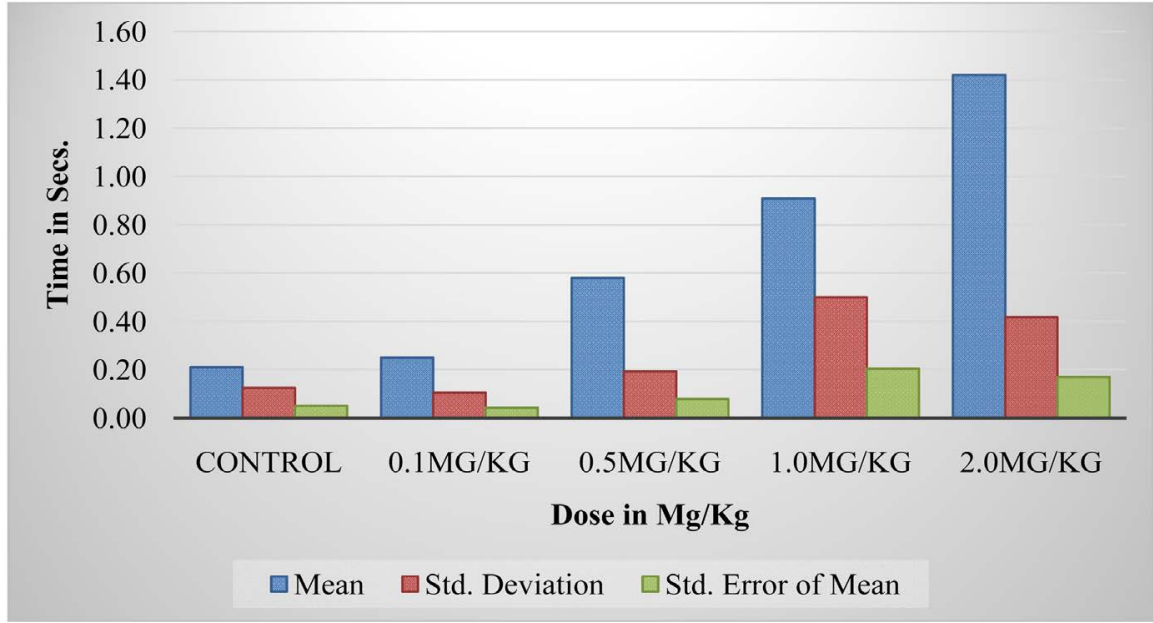

Figure 4. Effect of chloroquine on PT in Swiss Mice. Data are presented as: mean, standard deviation and standard error of mean. 
The second group of mice that were given $0.1 \mathrm{mg} / \mathrm{kg}$ of chloroquine had a decrease in APTT ( $0.89 \pm 0.50$ seconds) seen in Figure 3 , with a slight increase in PT $(0.25 \pm 0.11$ seconds) in Figure 4, but the difference is not so significant when compared to those of the mice in the control group $(0.21 \pm 0.13)$. This could be the result of elevated factor VIII.

The third group of mice which were given $0.5 \mathrm{mg} / \mathrm{kg}$ of chloroquine showed an increase in APTT ( $1.65 \pm 0.16$ seconds) above the reference value obtained for the control, while the PT $(0.58 \pm 0.19$ seconds) also increased above the reference value. This could be a pointer to Decreased or defective factor I (fibrinogen), II (prothrombin), V or X, severe liver disease, acute DIC. With both values above the reference values, the likely hood of spontaneous bleeding is there, indicating that at this dosage, chloroquine had begun to exhibit toxicity.

The group of mice with on $1.0 \mathrm{mg} / \mathrm{kg}$ dose of chloroquine, showed a significant increase in APTT (2.29 \pm 0.51 seconds) and an increase in PT $(0.91 \pm 0.50$ seconds), this shows defective factor I (fibrinogen), II (prothrombin), V or X, severe liver disease, acute DIC, with most likely, the presence of nonspecific inhibitors which may be Lupus anti-coagulants which binds to phospholipids found on the surface of platelets.

The last group of mice that were given $2.0 \mathrm{mg} / \mathrm{kg}$ of chloroquine showed increase in APTT ( $3.63 \pm 0.21$ seconds) and PT (1.42 \pm 0.42 seconds). At this dose, APTT value doubles the reference value of the control, while the PT is six times its reference value. Bleeding at this point may be more severe and may lead to thrombosis with life threatening complications such as stroke or a heart attack.

Chloroquine may be toxic at a dosage as low as $0.5 \mathrm{mg} / \mathrm{kg}$ with graded life threatening complications.

\section{Conclusion}

This study on the effect of chloroquine and naphthoquinone on the prothrombin time and activated partial thromboplastin time of Swiss Mice shows that naphthoquinone doses below $2.0 \mathrm{mg} / \mathrm{kg}$ may not be toxic, and reduce APTT while sustaining PT, but doses of $2.0 \mathrm{mg} / \mathrm{kg}$ and above may be toxic and cause spontaneous bleeding as well as liver damage among other conditions. While chloroquine may be toxic at a dosage as low as $0.5 \mathrm{mg} / \mathrm{kg}$ with some life threatening complications. Their use should be well monitored to avert any form of complications.

\section{Conflicts of Interest}

The authors declare no conflicts of interest regarding the publication of this paper.

\section{References}

[1] Milos, M., Coen Herak, D., Zupancic-Salek, S. and Zadro, R. (2014) New Quantitative aPTT Waveform Analysis and Its Application in Laboratory Management of 
Haemophilia A Patients. Haemophilia, 20, 898-904. https://doi.org/10.1111/hae.12492

[2] Sorensen, B. and Ingerslev, J. (2012) Dynamic APTT Parameters: Applications in Thrombophilia. Journal of Thrombosis and Haemostasis, 10, 244-250. https://doi.org/10.1111/j.1538-7836.2011.04600.x

[3] Furie, B. and Furie, B.C. (2005) Thrombus Formation in Vivo. The Journal of Clinical Investigation, 115, 3355-3362. https://doi.org/10.1172/JCI26987

[4] Hoffbrand, A.V., Pettit, J.E. and Moss, P.A.H. (2001) Essential Haematology. Blackwell Publishing, Oxford, 18-22.

[5] Mansouritorghabeh, H. (2015) Clinical and Laboratory Approaches to Hemophilia A. The Iranian Journal of Medical Sciences, 40, 194-205.

[6] Lewis, S.M., Bain, B.J. and Bates, I. (2006) Practical Hematology. 10th Edition, Churchill Livingstone Elsevier, Philadelphia, 389-400.

[7] Noguchi, M., Fuji, T. and Minamida, S. (1989) Comparative Studies of Measuring Condition of Activated Partial Thromboplastin Time and Contact Factors in Experimental Animals. Experimental Animals, 38, 221-229.

https://doi.org/10.1538/expanim1978.38.3_221

[8] Ryan, J., Orme, S.K., Waxier, H. and Ketcham, A. (2005) Successful Long Term Anticoagulation of Mice with PT Monitoring. National Cancer Institute, Institute of Health, Bethsada.

[9] Manco-Johnson, M.J., Nuss, R. and Jacobson, L.J. (2000) Heparin Neutralization Is Essential for Accurate Measurement of Factor VIII Activity and Inhibitor Assays in Blood Samples Drawn from Implanted Venous Access Device. Journal of Laboratory and Clinical Medicine, 136, 74-79. https://doi.org/10.1067/mlc.2000.107299

[10] Ramathan, K., Balakumar, B.S. and Panneerselvam, C. (2003) Effects of Ascorbic Acid \& a-Tocopherol on Arsenic-Induced Oxidative Stress. Human \& Experimental Toxicology, 21, 675-680. https://doi.org/10.1191/0960327102ht307oa

[11] Barry, E.L. and Mosher, D.F. (1990) Binding and Degradation of Blood Coagulation Factor XIII by Cultured Fibroblasts. J Biol Chem., 265, 9302-9307.

[12] Yuk, D.Y., Ryu, C.K., Hong, J.T., Chung, K.H., Kang, W.S., Kim, Y., Yoo, H.S., Lee, M.K., Lee, C.K. and Yun, Y.P. (2000) Antithrombotic and Antiplatelet Activities of 2-Chloro-3-[4-(ethylcarboxy)-phenyl]-amino-1,4-naphthoquinone (NQ12), a Newly Synthesized 1,4-Naphthoquinone Derivative. Biochemical Pharmacology, 60, 1001-1008. https://doi.org/10.1016/S0006-2952(00)00411-1

[13] Abdulrahaman, Y. and Dallatu, M.K. (2012) Evaluation of Prothrombin Time and Activated Partial Thromboplastin in Patients with Diabetes Mellitus. Nigerian Journal of Basic and Applied Science, 20, 60-63.

[14] Etukudoh, N.S., Opeyemi, O.O., Kunle-Alabi, O.T. and Adeyombo, F.B. (2019) Naphthoquinone Impairs Reproductive Functions in Plasmodium Berghei Berghei-Infected Male Swiss Mice. International Journal of Basic and Applied Sciences, 8, 1-4. https://doi.org/10.14419/ijbas.v8i1.10355

[15] Etukudoh, N., Kunle-Alabi, O., Akindele, O. and Bolarinwa, F. (2019) Haematological Effects of Chloroquine and Naphthoaquinone on Plasmodium berghei Infected Male Mice. International Journal of Scientific \& Engineering Research, 10, 923-927.

[16] Ansell, J.E., Hirsh, J., Poller, L., Bussey, H., Jacobson, A. and Hylek, E. (2004) The Pharmacology and Management of the Vitamin K Antagonists. The Seventh ACCP Conference on Antithrombotic and Thrombolytic Therapy, 126, 204S-233S. https://doi.org/10.1378/chest.126.3_suppl.204S 